Dossiê 9

Arte, Design e Artesanato: Ressignificações e Relacionamentos em Rede

DOI: $10.5965 / 25944630522021188$

\title{
CONTRIBUIÇÕES DA TEORIA DAS REPRESENTAÇÕES SOCIAIS PARA (RE)PENSAR O UPCYCLING NA ÁREA DA MODA
} Contributions from theory of social representantions to (re)think upcycling
in the fashion area

Contribuciones de la teoría de las representaciones sociales para (re) pensar el upcycling en el área de la moda

Rafaela Salgueiro ${ }^{1}$

Rita de Cássia Pereira Lima²

\footnotetext{
1 Professora do Curso de Moda da Fundação de Apoio à Escola Técnica do Estado do Rio de Janeiro (FAETEC). Mestranda do Programa de Pós-Graduação em Educação (PPGE) da Universidade Estácio de Sá-RJ, Linha de Pesquisa Representações Sociais e Práticas Educativas. Bolsista Capes-Prosup. Lattes: http://lattes.cnpq.br/6295797907904316; Orcid: http://orcid. org/0000-0003-4108-9681; e-mail: rafaelasalgueiro@hotmail.com

2 Doutora em Ciências da Educação/o pela Université René Descartes/Paris V. Professora no Programa de Pós-Graduação em Educação (PPGE) da Universidade Estácio de Sá-RJ, Linha de Pesquisa Representações Sociais e Práticas Educativas. Lattes: http://lattes.cnpq.br/4292907705126288; Orcid: http://orcid.org/0000-0002-3055-4915; e-mail: ritaplima2008@gmail.com
} 


\section{RESUMO}

O estudo, de natureza teórica, tem como objetivo propor reflexões sobre as contribuições da Teoria das Representações Sociais (TRS) para a abordagem do upcycling na área da Moda. A fundamentação teórica está pautada em elementos conceituais do upcycling e da TRS. O recorte do artigo se define por revisão de literatura não exaustiva sobre os dois temas, buscando mostrar sua articulação. A literatura mostra a relação do upclycling com o desenvolvimento sustentável, se contrapondo ao que se conhece por "reciclagem". Na perspectiva psicossocial da TRS, a maneira como sujeitos/grupos elaboram representações sobre upclycling, particularmente na área da Moda, indicam compreensões sobre significados que são construídos por meio das comunicações, expondo interesses específicos e revelando identidades culturais. $O$ artigo busca despertar reflexões que poderão respaldar futuros estudos empíricos, uma vez que temas relativos à sustentabilidade estão cada vez mais presentes na formação e no mundo do trabalho da Moda, e a compreensão de significados construídos por diversos grupos envolvidos se torna relevante nesse contexto.

Palavras-chaves: Representações sociais; Upcycling; Moda

\section{Abstract}

This theoretical study aims to provide reflections about the contributions of the Theory of Social Representations (TSR) to the approach of upcycling in Fashion. The theoretical foundation is based on the conceptual elements of upcycling and TRS. The cutout of the article is defined by the literature review on two topics, seeking to show their articulation. The literature shows the relationship of upclycling as sustainable development, in contrast to what is meant by "recycling". In the psychosocial perspective of the TSR, as the subjects / groups elaborate representations about upclycling, mainly in the fashion area, it indicates an understanding of meanings that are constructed throughout communication, exposing specific interests and revealing cultural identities. The article intends to awaken reflections that can support future empirical studies, once issues related to sustainability are increasingly present in training and in the world of fashion work, and the understanding of the meanings constructed by the various involved groups become relevant in this context.

Keywords: Social representations; Upcycling; Fashion

\section{Resumen}

El estudio, de carácter teórico, tiene como objetivo proponer reflexiones sobre los aportes de la Teoría de las Representaciones Sociales (TRS) al abordaje del upcycling en el ámbito de la Moda. La base teórica se fundamenta en elementos conceptuales de upcycling y TRS. El recorte del artículo se define mediante una revisión de la literatura no exhaustiva sobre los dos temas, buscando mostrar su articulación. La literatura 
muestra la relación entre upclycling y desarrollo sostenible, en contraste con lo que se conoce como "reciclaje". En la perspectiva psicosocial de TRS, la forma en que los sujetos / grupos elaboran representaciones sobre el upclycling, particularmente en el área de la moda, indica comprensiones sobre significados que se construyen a través de las comunicaciones, exponiendo intereses específicos y revelando identidades culturales. El artículo busca despertar reflexiones que puedan sustentar futuros estudios empíricos, ya que los temas relacionados con la sustentabilidad están cada vez más presentes en la formación y en el mundo del trabajo de la moda, y en este contexto cobra relevancia la comprensión de significados construidos por los diferentes grupos involucrados.

Palabras clave: Representaciones sociales; Upcycling; Moda 


\section{INTRODUÇÃO}

Esse artigo, de natureza teórica, teve como ponto de partida uma dissertação de mestrado com o objetivo de investigar representações sociais de upcycling por professores e alunos de um curso de Produção de Moda do Rio de Janeiro. Devido à emergência da temática na área da Moda, optamos por um recorte, abordando reflexões sobre as contribuições da Teoria das Representações Sociais (TRS) para a compreensão de significados sobre upcycling construídos por diversos grupos sociais.

Definido em 1987 pela Comissão Mundial sobre o Meio Ambiente e Desenvolvimento como aquele que "atende às necessidades do presente sem comprometer a possibilidade das futuras gerações de atingir suas próprias necessidades" (BRUNDTLAND, 1991, p. 46), o desenvolvimento sustentável vem sendo abordado em diversas áreas do conhecimento. No meio empresarial, por exemplo, está pautado no tripé justiça social, viabilidade econômica e preservação ambiental (ELKINGTON, 1997). De acordo com Manzini e Vezzoli (2008, apud Lima 2019, p. 17) "no design, passou a ser abordado como algo indissociável da prática de projetos de produtos e serviços".

Na área da Moda, o desenvolvimento sustentável refere-se a um modelo de produção que diminui impactos sociais e ambientais, evitando o formato linear de produção, caracterizado pelo ciclo: extração de matérias-primas; fabricação; distribuição; uso; descarte. Há preferência pelo formato circular de produção, considerando, desde as fases iniciais do projeto, estratégias para o fim de vida do produto "que visam devolver os materiais com segurança de volta ao ambiente ou a um sistema de produção em circuito fechado" (GWILT, 2012, p. 78). A peça descartada poderá, assim, retornar ao ciclo como matéria prima.

O impacto ambiental da indústria da Moda é um dos seus maiores problemas. O abuso de recursos naturais, destacando-se o uso excessivo de água, a poluição através dos componentes químicos, o uso de fibras sintéticas que demoram centenas de anos para se degradar e a grande emissão de gases de efeito estufa são exemplos. Além disso, uma forte valorização da efemeridade da Moda deu origem ao fast fashion, modelo por meio do qual se produzem roupas baratas, de má qualidade e curta durabilidade. Esse consumo desenfreado alimenta trabalhos em condições precárias e análogos ao escravo (RUDOLPH, 2017), além de um ritmo de consumo na contramão do desenvolvimento sustentável.

Embora caminhos e soluções pareçam difíceis para enfrentar o problema, há várias propostas e ações em curso. Estudos de tecnologias têxteis de menor impacto ambiental e reutilização de resíduos já vêm sendo considerados e aplicados por algumas indústrias. As fabricantes de tecido Tavex Corporation e o grupo Cedro Têxtil têm programas de reciclagem dentro da própria empresa. As marcas brasileiras Osklen e a de jeanswear Éden investem em pesquisas de novas tecnologias e processos de produção (ZONATTI, 2013). 
Do lado do consumidor, diversos modos de veiculação de conhecimentos são crescentes. O Fashion Revolution, movimento global sem fins lucrativos presente em mais de 100 países, mobiliza milhões de pessoas a se questionarem sobre a origem de suas roupas com a campanha "Quem fez minhas roupas?", denunciando as condições de trabalho que movimentam a indústria do fast fashion. É possível observar hoje, circulando pelas redes sociais, postagens fomentando a valorização de produtores artesanais, pequenas marcas que trabalham pensando na sustentabilidade, compras de roupa de segunda mão e movimentos de trocas de roupa que substituem a compra de um artigo novo.

Definido em 2008 por Kate Fletcher em seu livro Sustainable Fashion and Textiles: Design Journeys, o slow fashion, ou moda lenta, surge como um contraponto ao fast fashion. Para Lima (2019, p. 28):

O slow fashion contempla a concepção, produção e o consumo de produtos de moda, considerando a sustentabilidade ambiental e social, por meio da produção de peças de vestuário que conjuguem apelo estético e consciência ambiental, social e econômica.

Alinhado com o slow fashion, com a economia circular e com a preservação dos recursos naturais em prol do desenvolvimento sustentável, o upcycling vem ganhando espaço no mercado da moda. O termo foi usado pela primeira vez em 1994, em uma entrevista de Reiner Pilz, executivo da empresa Pilz GmbH, para o periódico britânico Salvo News. O empresário fez uma brincadeira, um jogo de palavras, criticando o modelo de utilização de matéria-prima pela construção civil, que desperdiçava muito material que ainda poderia ser utilizado de outras formas. "Reciclagem [...] eu chamo isso de downcycling. Eles quebram tijolos, concreto, eles quebram tudo. O que precisamos é de upcycling, onde é dado mais valor para os produtos antigos, e não menos" (SALVO NEWS, 1994, p. 11).

Upcycling pode ser entendido como uma alternativa ecológica de dar um novo significado e função a determinado material que seria descartado, transformando algo que está no fim de sua vida útil em algo novo e de maior valor, sem passar por nenhum dos processos físicos ou químicos característicos da reciclagem (VIALLI, 2013, citado por PINHEIRO, et al, 2018). Diferente da reciclagem, processo que gera um material de mesmo valor do original que lhe deu origem, como o vidro e o alumínio, e do downcycling, que reaproveita materiais descartados gerando um material com menor qualidade ou menor valor agregado, a exemplo do papel, o upcycling é o processo em que o reaproveitamento do material descartado gera outro material de maior qualidade ou maior valor agregado (BRAUNGART; MCDONOUGH, 2014).

O objetivo do upcycling é evitar o desperdício de materiais potencialmente úteis, fazendo uso dos já existentes, o que reduz o consumo de novas matériasprimas durante a criação de novos produtos (BRAUNGART; MCDONOUGH, 2014) e proporciona outro destino ao material que antes iria para o lixo, característica 
principal da economia circular. Falando especificamente em Moda, o upcycling consiste em utilizar peças antigas ou resíduos de produção que seriam descartados e fazer deles matéria-prima para novas roupas e acessórios, impedindo a geração de lixo e dispensando a necessidade de novas matérias-primas poluentes.

Nicolini (2017) descreve a grande variedade de materiais que pode ser usada como upcycling no processo criativo de marcas de moda. Em um levantamento feito para o livro + Sustentabilidade às marcas de moda (MAROTTO, 2017), a autora afirma que, tratando exclusivamente dos acessórios, por exemplo, podemos encontrar bijuterias feitas de borracha, retalhos têxteis e de couro provenientes da indústria, sobras de madeira, papel, resíduos eletrônicos, correias de bicicleta, sobras de poda de plantas, jeans, brinquedos, cordas náuticas descartadas, sobras e retalhos de acrílico industrial, cápsulas de café, chapas de raios-X e restos de cerâmica. A autora também faz referência a bolsas e pochetes que usam como matéria-prima retalhos têxteis oriundos de diversas fontes como, retalhos vinílicos de indústrias, malotes dos correios em sarja e brim, jeans, cintos de segurança, estofamento de carros, lona de banners descartados, velas descartadas de barcos de competições esportivas, nylon de paraquedas, e redes e ilhoses de pesca.

Diante do exposto acima, fica evidente a contribuição de práticas de upcycling para a preservação ambiental. No entanto, Nicolini (2017) lembra ainda que a produção de peças e acessórios a partir do upcycling está diretamente ligada às manualidades, e nos mostra como o upcycling contribui também para outro pilar do desenvolvimento sustentável: a justiça social. Sobre o upcycling, a autora nos traz que é praticamente impossível encontrar marcas que, em pelo menos uma parte da cadeia de produção, não utilizem de processos manuais, como técnicas tradicionais clássicas de artesanato, fazendo parcerias com cooperativas, gerando renda e valorizando o conhecimento dos profissionais envolvidos. E complementa ao se referir a marcas que:

\footnotetext{
buscam profissionais com especificidades concomitantes ao produto ou material com o qual trabalham, como: sapateiros, relojoeiros, marceneiros clássicos e lapidadores, para treinamento e/ou contratação. Todas as marcas, através do upcycling, de alguma forma promovem e difundem a produção cuidadosa, delicada e ética de uma peça feita ou acabada pelas mãos de alguém. (NICOLINI, 2017, p. 166)
}

Fundamentado em conceitos de desenvolvimento sustentável, o termo upcycling começa a surgir nas escolas de formação, especialmente de Design e de Moda, provocando assim um processo de familiarização em relação ao tema e (re) construção de significados. Tal processo é propício para estudos de representações sociais sobre o objeto, ou fenômeno upcycling, uma vez que entendemos que as representações sociais são "um conjunto organizado e hierarquizado de julgamentos, de atitudes e de informações que um determinado grupo social elabora a respeito 
de um dado objeto" (ABRIC, 1996, p. 12). Este objeto, quando desperta o interesse de indivíduos/grupos e passa a fazer parte de suas comunicações, pode gerar um conhecimento do senso comum. Tal conhecimento é considerado uma representação social. Em face desse tema que emerge principalmente na área da Moda, estudar as representações de diversos grupos que compõem o setor apresenta relevância acadêmica.

Jodelet (2001) afirma que criamos representações não apenas para nos ajustarmos ao mundo à nossa volta, mas também para dominá-lo física ou intelectualmente, sabermos como nos comportar, identificar e resolver os problemas que se apresentam. Para a autora, representações sociais são sistemas de interpretação que regem nossa relação com o mundo e com os outros. Elas orientam e organizam as condutas e as comunicações sociais. E, segundo Alves-Mazzotti (2008a, p. 20/21), "o estudo das representações sociais investiga como se formam e como funcionam os sistemas de referência que utilizamos para classificar pessoas e grupos e para interpretar os acontecimentos da realidade cotidiana". Elas estão relacionadas à linguagem, à ideologia e, principalmente, às condutas e às práticas sociais.

Nos itens seguintes serão desenvolvidos elementos teóricos do upcycling e da TRS. Buscamos evidenciar as contribuições que essa relação teórica pode trazer particularmente para a área da Moda, tanto em seus aspectos formativos e acadêmicos, quanto em relação ao mundo do trabalho.

\section{DESENVOLVIMENTO SUSTENTÁVEL, UPCYCLING E MODA}

O desabamento do edifício Rana Plaza em abril de 2013, em Bangladesh, descortinou uma grave questão que envolve a indústria da Moda: as condições de trabalho de seus funcionários. O desastre, que vitimou 1.134 trabalhadores, em sua maioria mulheres e crianças, trouxe à tona as condições de exploração humana, condições análogas à escravidão, e de escravidão contemporânea na qual se sustenta o fast fashion. (RUDOLPH, 2017; BERNAL, 2019).

A tragédia provocou um profundo debate sobre consumo consciente, desenvolvimento sustentável e slow fashion por profissionais do setor em todo mundo, culminando, no ano seguinte, no Fashion Revolution, movimento internacional de grandes proporções que realiza pesquisas que mostram os impactos sociais e ambientais da indústria da Moda e movimenta ações que fomentam trabalho digno, remuneração justa, transparência nos processos e a conscientização ambiental através da sustentabilidade e da economia circular.

Embora o nome possa sugerir uma antítese, o slow fashion não é exatamente o oposto do fast fashion, visto que não se ocupa apenas em produzir de forma mais lenta. O termo surgiu em referência ao termo slow food, surgido nos anos 80 , relacionado a hábitos alimentares que prezavam por qualidade, procedência e modo de preparo (MARTELI at al, 2018). Para Fletcher e Grose (2019, n.p.), lento, nesse contexto, não se refere a velocidade, mas a uma "visão de mundo diferente, que especifica um conjunto distinto de atividades de moda para promover o prazer da variedade, a multiplicidade e a importância cultural da moda dentro de limites biofísicos". 
É importante entender que o movimento slow fashion é uma contra tendência ao consumismo, mas não é contra o consumo, uma vez que defende um consumo consciente, desconectado de tendências de moda efêmeras e pautado em qualidade e durabilidade. A comercialização em pequenas quantidades e o trabalho artesanal são pontos importantes do movimento. O ateliê tem papel fundamental nos princípios do slow fashion, pois vai ao encontro de um sistema de produção que visa amenizar os problemas causados pelo fast fashion, através de práticas sustentáveis de produção e consumo (MARCHIORO 2010, apud MARTELI et al, 2018).

Braungart e McDonough escrevem, em 2002, a principal obra de referência quando se fala hoje em projetos de desenvolvimento sustentável. O título Cradle to Cradle (2014) - em tradução livre: "Do berço ao berço" - faz uma referência ao formato circular de produção onde um produto, ao final da sua vida útil, em vez de ser descartado, retorna como matéria-prima da cadeia produtiva, seja através da reciclagem, do upcycling ou do downcycling. Os autores explicam que o conceito Cradle to Cradle vai muito além de regras governamentais de reciclagem ou de simplesmente se pensar quimicamente no impacto ambiental das matérias-primas ou dos processos de um projeto. Eles defendem pensar, sobretudo, o que será feito desse produto após seu ciclo de uso, seja ele um utensílio doméstico, um piso, um móvel ou uma roupa.

Elkington (1997, p. 35) define a sustentabilidade como "o princípio de garantir que nossas ações hoje não limitem o leque de opções econômicas, sociais e ambientais disponíveis para gerações futuras". Afirma que muitas pessoas pensam saber o que é a sustentabilidade, porém a definem de formas muito diferentes. Segundo o autor, empresas líderes têm se empenhado para descobrir o que significa exatamente falar em sustentabilidade para o processo de desenvolvimento de um produto, para todo um setor industrial, ou mesmo para uma economia inteira.

Trazendo a sustentabilidade para o universo da moda, Silveira (2019, p.21) afirma: "a Moda Sustentável não possui uma conceituação formal e desenvolvida, mas, através da revisão de literatura, encontramos apenas características, ideais, processos e filosofias, uma série de estímulos que é preciso sistematizar". O autor se pauta na definição de Kozlowski, Searcy e Bardecki (2018, apud SILVEIRA 2019, p. 21), que consideram moda sustentável aquela que prioriza todas as fases do ciclo do vestuário, dentro de um "pensamento sistêmico que reduz os impactos negativos e procura criar impactos sociais, econômicos e ambientais positivos."

No cenário nacional, Silveira (2019, p.12) cita as Lojas Renner S.A como exemplo de empresa de Moda atenta ao padrão mundial e abrindo espaço não apenas para pequenas coleções sustentáveis, mas buscando desenvolver uma política de sustentabilidade que abranja "desde a promoção de pesquisa e inovação para o uso de matérias-primas mais sustentáveis, até o desenvolvimento de iniciativas para estímulo à economia circular a partir da reintrodução de materiais, após seu uso, ao ciclo produtivo".

Sobre o fim da vida útil dos produtos de Moda, Köhler Schulte et al (2013) explicam que muitas fibras podem ser recicladas gerando novas fibras. Fletchere Grose 
(2019) acrescentam que, na maioria das vezes, esse é um processo de downcycling, pois o tecido acaba sendo submetido a ações químicas e transformado em fibras mais curtas, formando fios mais volumosos e de baixa qualidade que acabam servindo como material de isolamento térmico e enchimento de colchões.

Alinhado comos preceitos da sustentabilidade, do slowfashione da economia circular, o upcycling pode ser entendido, como um processo de reaproveitamento de resíduos e materiais obsoletos que seriam descartados, originando um produto de maior qualidade ou valor tangível agregado. Por sua capacidade de reduzir o consumo de energia e de matérias-primas e de gerar recursos sustentáveis para produção e consumo, o upcycling tem recebido mais atenção de pesquisadores e empresários nos últimos anos. Além disso, novos empreendimentos estão nascendo já usando a prática como ferramenta principal e outros se especializando em promover e aplicar a técnica para empresas interessadas em implementar o upcycling em seus processos. É o caso das internacionais TerraCycle, FREITAG, Reclaimed, The Upcycling Trading Company e Hipcycle, para citar alguns exemplos (SUNG, 2015).

Importante entender que todo reaproveitamento de material, fazendo dele uma nova matéria-prima ou um novo produto, e resultando em algo de maior valor evitando o descarte, é considerado upcycling. Isso inclui desde adicionar um polímero com reforço de fibra e aditivos a plásticos reutilizados para aumentar a qualidade do plástico e reutilizá-lo em contexto industrial (SUNG, 2015) até aquela roupa que furou e, para não a perder, a própria pessoa aplica um bordado.

De acordo com Avila et al (2018, p.21), por serem finitos e únicos, o uso de tais recursos para gerar novos produtos resulta em "pequenas quantidades de produtos com muita exclusividade e valor afetivo". Para Silveira (2019, p. 12), o upcycling "parte da seleção de materiais que perdem seu valor de mercado, mas com características propícias ao reaproveitamento e modificação, e os ressignifica de maneira criativa, sustentável - bem como incentiva a criação de peças únicas e exclusivas".

São muitos os materiais possíveis de serem usados com a técnica de upcycling em peças de Moda. No cenário internacional destacamos a ZWD, marca que utiliza resíduos têxteis de fábricas em Nova lorque unindo pequenos retalhos de tecido para formar peças de roupas e/ou estampas para as mesmas. A estilista estoniana Reet Aus também trabalha com upcycling de resíduos têxteis na marca que leva seu nome, além de cooperar com a gigante Beximco, fabricante de vestuário em Bangladesh, implementando um projeto de upcycling que utiliza peças reprovadas pelo controle de qualidade para montar peças upcycled feitas à mão pelos trabalhadores locais dentro da própria fábrica em Bangladesh (SILVEIRA 2019).

O britânico Christopher Raeburn, cuja marca leva seu sobrenome, trabalha com resíduos têxteis e produtos acabados ao fim de sua vida útil. A Jamaicana Jessica Ogden destaca-se por trabalhar usando apenas roupas antigas como matéria-prima. Em Los Angeles, Ayler Young usa sobras de tecidos da grife Chanel para montar jaquetas bomber. Na Suíça, os irmãos Freitag usam lonas de caminhão, câmaras de 
bicicletas e cintos de segurança descartados para criar bolsas. A britânica Elvis \& Kresse iniciou seu trabalho de upcycling utilizando mangueiras de incêndio que iriam para o lixo, e hoje ampliou a gama de materiais para forros de paraquedas, banners, retalhos de couro entre outros. A Japonesa Seal utiliza câmaras de pneus de veículos de grande porte para criar bolsas, sapatos e acessórios e, utilizando os mesmos materiais, a britânica New Globe Traveller fabrica bolsas de viagem. Fechando os exemplos do cenário internacional, trazemos a grife do belga Martin Margiela, que em 1990 levou às passarelas cortiça, metal e até cacos de pratos (CARREIRA, 2019). Posteriormente, criou o segmento "artesane" no qual suas peças eram feitas artesanalmente a partir de peças de roupas de segunda mão e antiguidades (BERLIM, 2012).

Gilson Martins é um dos pioneiros no cenário nacional. Desenvolveu uma mochila feita de restos de estofamentos com os quais seu pai trabalhava no início da década de 1980. Desde então, tem utilizado como matéria-prima forro de teto de carro, chão de Kombi, assento de ônibus, mangueiras de borracha, lonas de cadeira de praia, entre outros materiais (BERLIM, 2012). Ainda hoje, o estilista carioca utiliza as sobras das próprias produções para aplicar em seus produtos.

O movimento tem ganhado força no Brasil e muitas marcas pautadas no conceito do upcycling surgiram nos últimos anos. Com maior visibilidade, podemos destacar a Insecta Shoes, que desde 2014 utiliza roupas usadas, resíduos de produção e borracha reaproveitada na confecção de seus calçados. O Re-Roupa, cujo slogan "roupa feita de roupa" já evidencia seu principal material de trabalho e, além da venda de suas peças, promove oficinas de upcycling e desenvolve projetos para marcas renomadas como Farm e Fábula, transformando em novas peças o que essas empresas consideravam resíduos. A Think Blue utiliza apenas calças jeans como matéria-prima para suas roupas. A Comas, da uruguaia Augustina Comas, sediada em São Paulo, usa camisas masculinas reprovadas no controle de qualidade de indústrias para desenvolver saias, tops, calças e chemises, masculinas e femininas. A Zerezes produz óculos de sol feitos de madeira que iria para o lixo. A Colibri é uma rede que trabalha com artesãos de Porto Alegre produzindo peças a partir de resíduos têxteis, jeans e lonas de caminhão.

Os parágrafos acima citam apenas alguns exemplos de marcas que utilizam o upcycling em suas atividades. Importante lembrar que, na maioria das vezes, esse trabalho é feito em parceria com Organizações Não Governamentais (ONG's), cooperativas de artesãs, costureiras ou catadores de materiais reciclados, como é o caso do Ecossistema de Moda Sustentável do Rio Grande do Sul, que tem a função de intermediar o trabalho de diversos agentes ligados aos mesmos ideais. Participam da ação o Instituto Renner, a Universidade do Vale do Rio dos Sinos UNISINOS, o Banco de Tecidos da região, associações de costureiras da Vila Bom Jesus e arredores, empreendedores, designers e marcas ligadas à confecção de moda sustentável como a Envido, a Herself e a Colibri. De acordo com Silveira (2019, p. 13): "Esse ecossistema vem funcionando como uma plataforma de trocas e encontros onde os diversos atores se conectam, criam e desenvolvem projetos entre si, de acordo com suas necessidades e capacidades". 
O panorama exposto nesse item mostra o contexto social, econômico e cultural em que o upcycling se insere em âmbito nacional e internacional, provocando construções de significados e ressignificações na área da Moda, por diversos sujeitos e grupos que são afetados por esse objeto. É nesse sentido que a TRS pode oferecer contribuições acadêmicas, conforme apresentado nos itens seguintes.

\section{ELEMENTOS DA TEORIA DAS REPRESENTAÇÕES SOCIAIS}

Para o psicólogo social Serge Moscovici (2012), um dos fundamentos da TRS é considerar as representações sociais como construções simbólicas pelas quais sujeitos e grupos atribuem significados a determinado objeto, de acordo com suas crenças, valores, modelos e símbolos de seus grupos de pertença e de referência. Representações essas que "circulam nos discursos, são trazidas pelas palavras e veiculadas em mensagens e imagens midiáticas, cristalizadas em condutas" (JODELET, 2001, p. 18).

Comportando as inserções sociais e culturais dos sujeitos/grupos, o estudo das representações sociais focaliza o conhecimento do senso comum, compreendendo como ideias sobre determinado objeto começam a se formar em contextos específicos, de acordo com os valores e crenças comunicados em interações grupais. Aborda também a (re)criação de significados sobre o novo objeto e as práticas dos grupos sobre ele. De acordo com Jodelet (2001, p. 26):

As representações sociais devem serestudadas articulandoelementos afetivos, mentais e sociais e integrando, ao lado da cognição, da linguagem e da comunicação, a consideração das relações sociais que afetam as representações e a realidade material, social e ideal sobre a qual elas intervêm.

O processo de familiarização de novos conceitos que vão formando uma representação social pode ser mais complexo do que parece à primeira vista. Para dar uma feição familiar a esses novos conceitos é necessário colocar em funcionamento dois mecanismos do pensamento, processos formadores das representações sociais que envolvem as dimensões cognitiva e social, a memória e significados anteriores: a ancoragem e a objetivação. O primeiro tenta enraizar ideias estranhas classificandoas e nomeando-as de acordo com o que já é conhecido socialmente e culturalmente. O segundo substitui o conceito em uma imagem, materializando uma ideia abstrata (MOSCOVICI, 2015). Tais imagens, que buscam conceituar o abstrato, são integradas no que Moscovici (1961, 1976 e 2012) chamou de modelo, ou núcleo figurativo, o qual sintetiza e organiza os elementos da representação com uma forte característica imagética. Jodelet (1984) se refere a esse núcleo como um esquema, derivado da objetivação, que concretiza os elementos do objeto representado.

Representar um objeto é reconstituí-lo, expressando o mundo visto por 
sujeitos/grupos. As representações mostram que aspectos ausentes do objeto podem ser acrescentados, e que aspectos presentes podem ser modificados, de acordo com os universos sociais e culturais dos sujeitos. Quando um objeto exterior entra no campo de interesse das pessoas, pode haver desequilíbrio em relação ao já pensado, provocando a necessidade de associar o conteúdo estranho a um conteúdo conhecido, tornando familiar o insólito. Desse modo, ao representar um objeto, sujeitos/grupos Ihe concedem o estatuto de signo e o tornam significante quando produzem um conhecimento sobre ele (MOSCOVICI, 2012).

As representações sociais se apresentam comoum conjunto de proposições, de reações, de avaliações presentes em discussões coletivas. Esse conjunto se organiza diferentemente de acordo com as classes, as culturas, a formação dos grupos. Moscovici (2012) se refere a uma característica tridimensional das representações sociais: a) a informação: organização dos conhecimentos do grupo sobre o objeto, recebida por diversos canais de comunicação; b) o campo: refere-se à imagem, ao modelo social, apresentando conteúdos que expressem aspectos do objeto, com unidade hierarquizada de elementos; c) atitude: orientação global em relação ao objeto, indicando posições dos sujeitos/grupos. Um aspecto a ser destacado nessa análise dimensional é que a representação é produzida e gerada coletivamente, contribuindo para a orientação das condutas e das comunicações sociais (MOSCOVICI, 2012).

Alves-Mazzotti (2008a, p. 34), propõe que, ao desenvolver um estudo em representações sociais, o pesquisador precisa ter em mente a proposta de responder a uma dupla questão que está na base da teoria: "como o social interfere na elaboração psicológica que constitui a representação e como essa elaboração psicológica interfere no social". Segundo a autora, isso reforça o interesse em uma modalidade do pensamento social que tem um aspecto constituído, o produto, mas também o aspecto constituinte, que são os processos psicossociais que a geram. $A$ autora chama a atenção para a importância de ultrapassarmos "o nível da constatação sobre o que se passa na cabeça dos indivíduos, para procurar compreender como e porque essas percepções, atribuições, atitudes e expectativas são construídas e mantidas" (idem, p. 20). Ela defende que as pesquisas fundamentadas na TRS não acontecem em um vazio social, à medida em que envolvem processos simbólicos que consideram o sujeito com seu mundo interior, mas ao mesmo tempo situado em um contexto social no qual interage e (re)constrói significações.

Em estudos de representação social não há separação entre os universos individual e exterior, visto que sujeitos e grupos estão inseridos em um campo social e cultural comum. Ou seja, o objeto se insere em um contexto ativo, dinâmico, em que o sujeito/grupo se situa no universo social e material, e se constitui conforme constrói significados sobre o mundo por meio das interações (MOSCOVICI, 2012). Moscovici (1984) propõe como fundamento epistemológico da TRS a formação da representação social em uma perspectiva triádica que articula "Sujeito-Outro-Objeto". Essa tríade mostra claramente a articulação entre as dimensões psicológica e social na elaboração da representação, em uma abordagem psicossocial. 
Após 50 anos da primeira edição da obra de Moscovici(1961), Jodelet(2011) chama atenção para a fecundidade da TRS, reforçando seu caráter interdisciplinar. A teoria tem origem na psicologia social, mas refere-se também a outras ciências sociais, como a sociologia, a antropologia, a história, a filosofia e a ciência. A autora enfatiza a originalidade de Moscovici ao discutir as representações como formas de conhecimento, associando pensamento e comportamentos a processos de informação e de expressão ideológica, assim como a aspectos cognitivos. A contribuição está também em destacar o papel da comunicação, que origina os processos formadores das representações sociais, a objetivação e a ancoragem.

Sá (2011) enfatiza a preocupação de Moscovici quanto a explicar a persistência de pensamentos "irracionais" nas sociedades contemporâneas com suas instituições pautadas no pensamento científico. Para o autor, Moscovici se interessa por esse conhecimento do senso comum como objeto científico devido à sua presença nas comunicações e nos comportamentos da vida cotidiana. Moscovivi (2001) buscou argumentos na antropologia de Lévy-Brühl, que distinguia "mentalidade primitiva" e "mentalidade civilizada"; e na psicologia de Piaget, que fazia distinções entre "pensamento infantil" e "pensamento adulto". Com base particularmente nesses dois autores, Moscovici foi estabelecendo relações entre o conhecimento científico e o conhecimento do senso comum, tendo como questão principal o modo como uma teoria científica é substituída por uma representação social, em função de características grupais e culturais (SÁ, 2011).

A TRS reintroduz a relação com o Outro na Psicologia Social. Desse modo, comportamentos e pensamentos passam a ser estudados em um quadro social, com foco no grupo, valorizando-se as dimensões culturais e históricas nos estudos psicossociais. Em Moscovici, o sujeito é ativo, construtor da realidade social e nela construído. Importante lembrar os três aspetos sociais que determinam as representações, propostos por Moscovici:a) pressão à inferência: quando as interações grupais influenciam o posicionamento dos sujeitos, instando-os a expressarem opiniões para garantirem a comunicação e se sentirem parte do grupo; b) focalização: quando o sujeito fica atento a aspectos do ambiente social, relacionando-se com dados da realidade em função do acesso à informação e da estratificação de seus valores; c) defasagem e dispersão de informação: depende das condições de acesso e do tipo de exposição às informações sobre o objeto, por exemplo, obstáculos de transmissão e barreiras educativas. (SANTOS, 2005).

Por fim, não é possível finalizar esse item teórico sobre a TRS sem menção ao conceito de representação coletiva de Durkheim, o qual Moscovici (1961, 1976, 2012) retoma criticamente para fundamentar sua teoria. Moscovici (2003) parte de uma crítica à concepção durkheimiana de vida social, cuja visão de sociedade expressa coerência e práticas reguladas por crenças, saberes, normas e linguagens produzidas por ela mesma, e em que sua autonomia é entendida como meio natural do homem. Como afirmam Rateau et. al. (2012), ao substituir o termo representação "coletiva" por "social", Moscovici (1976) pretendeu enfatizar as interações que ocorrem entre os indivíduos na sociedade, quando elaboram representações, consideradas autônomas 
em relação à sociedade.

A TRS tem despertado o interesse de pesquisadores, principalmente da Psicologia Social e de outras ciências sociais, porque oferece elementos de compreensão da disseminação do conhecimento, da relação entre pensamento e comunicação e da gênese do senso comum. Desde quando foi proposta, em 1961, tem sido objeto de diferentes desenvolvimentos conceituais, com enfoque plurimetodológico que pode fundamentar ampla possibilidade de estudos sobre questões sociais, tanto em abordagens qualitativas quanto quantitativas. Esta condição é facilitada por sua natureza interdisciplinar, que inclui áreas como sociologia, antropologia, história, geografia, economia, sempre privilegiando os sistemas simbólicos (RATEAU et. al., 2012).

É no âmbito das representações sociais particulares a uma cultura que pretendemos situar os estudos sobre upcycling, considerando o modo como conhecimentos sobre esse objeto são gerados e compartilhados por membros de grupos diversos, no decurso das comunicações. Rateau et. al. (2012) afirmam que a TRS é uma teoria de vinculação social que oferece elementos para percebermos o que conecta as pessoas ao mundo e aos outros, constituindo-se em teoria essencial para compreender questões sociais. É dentro desta perspectiva teórico-metodológica que situamos a relevância de estudos sobre upcycling, sobretudo na área da Moda.

\section{A TEORIA DAS REPRESENTAÇÕES SOCIAIS COMO POSSIBILIDADE PARA ESTUDAR O FENÔMENO DO UPCYCLING NA MODA}

A presença do upcycling na área da Moda, especialmente a partir da sugestão do termo por Reiner Pilz, em 1994, para designar a prática de valorizar produtos antigos e sobras de matéria prima sem desperdiçá-los, supõe vários significados que podem ser atribuídos a ele, às vezes próximos de "reciclagem", de slow fashion, ou de downcycling, sugerindo polissemia em função da inserção de pessoas/grupos em determinados contextos. A TRS é de grande relevância para compreender a construção desses significados, principalmente porque o estudo das representações sociais não é valorativo, no sentido de julgar se os significados estão certos ou errados em relação ao parâmetro de referência, no caso, a conceituação de upcycling por especialistas da área. O que interessa é compreender como se forma uma representação social sobre o objeto em um contexto específico no qual as pessoas interagem, assentado em informações, conhecimentos, normas e valores sociais e culturais.

Quando propôs a TRS, Moscovici $(1961,1976,2012)$ já afirmava que todo conhecimento pressupõe uma prática de um sujeito conhecedor. Na formação das representações, cada sujeito/grupo tem como ponto de partida observações, depoimentos acumulados a respeito de fenômenos ou objetos de interesse. Diversas fontes, como jornalistas, cientistas, políticos, veiculam notícias que afetam as pessoas, influenciando para que elas produzam significados sobre os temas abordados. Ao se 
tornar um saber interno, eles passam a integrar as comunicações que ocorrem, por meio de interações, no seio de uma sociedade, de uma cultura. Como afirma o autor, as pessoas não especialistas resumem, recortam, classificam assuntos quando se deparam com certas situações, não com o objetivo científico, mas de se sentirem informadas. É assim que as representações sociais surgem de "cientistas amadores", que muitas vezes se prendem a ideias feitas ao darem sentido a fenômenos sociais. (MOSCOVICl, 2012).

Essas características da TRS são fundamentais para a compreensão de significados elaborados sobre upcycling por grupos diversos situados no universo da Moda. Destacaremos aqui as temáticas da pesquisa e da formação em Moda, que se inserem no campo da Educação, onde muitos estudos sobre representações sociais têm sido realizados. Como afirma Borges (2018, p. 49), "os saberes, desafios e dificuldades, em diferentes tempos e contextos, que envolvem uma área multidisciplinar, como é o caso da moda, constituem um campo importante para pesquisa em educação".

De acordo com Campos (2017), o Brasil tem uma contribuição significativa em estudos que conjugam a TRS e a Educação. Para o autor, a TRS pode ajudar a pensar as práticas educativas e a relação entre os sujeitos coletivos e instituições escolares. Lima e Campos (2020) ressaltam a importância de estudarmos as representações sociais na Educação, reforçando que essas contribuem para a compreensão sobre como se constrói uma visão de mundo quando um objeto emerge socialmente no contexto dos sujeitos. Nas palavras de Sousa (2002, p. 297):

Ao analisar as representações sociais que constituem o cotidiano, o pesquisador/educador procura sempre vislumbrar possibilidades de promover a tomada de consciência que permita reorientar práticas educativas, tornando-as efetivamente comprometidas com o desenvolvimento do aluno.

Como isto poderia acontecer na abordagem do upcycling em cursos de formação em Moda? Esse artigo teórico é fruto de uma dissertação de mestrado com objetivo de investigar representações sociais de upcycling por alunos e professores de um curso de Moda do Rio de Janeiro. Consideramos relevante compreender como o objeto upcycling está sendo apropriado, familiarizado e referenciado por esses sujeitos e que práticas estão sendo orientadas pelas representações formadas. A fundamentação na TRS pode contribuir, por exemplo, para o aprofundamento das discussões sobre upcycling e suas implicações no tripé viabilidade econômica, preservação ambiental e justiça social no qual se ampara a sustentabilidade.

É importante que essas discussões sejam ampliadas na área da Moda, a qual, por abrir possibilidades de análise dos grupos sociais e das influências do meio sobre o indivíduo, se constitui como referência nos estudos da psicologia e da sociologia (FREITAS, 2001). Lipovetsky (1989) também expressa essa relação quando afirma ser a moda um fenômeno que encontra sua força na lógica do social. 
A relação entre TRS e Moda, segundo Borges (2018), é de grande valia pois, uma vez compreendido que o que se pensa sobre a moda, compreende-se o que pensa o profissional que nela atua. Para a autora,

se moda é glamour, é mais evidente que se acredite que ser profissional desta área é lidar com glamour, passarelas e fama. Se, por outro lado, a moda for consumismo e exagero, o profissional da área seria aquele que constrói produtos supérfluos, e assim por diante (BORGES, 2018. p. 86).

A abordagem da sustentabilidade, consequentemente do upcycling, se insere nesse universo de formação. A relação da Moda com grupos e contextos culturais distintos também pode ser depreendida das palavras de Sales (2007, p.4): "A moda não é somente um produto industrial, não é somente um produto para ser comercializado, não está inserida em grandes redes produtoras, mas também pertence a outra esfera, ou seja, à esfera do simbólico".

Em consonância com os apontamentos acima, várias são as possibilidades para estudarmos o fenômeno do upcycling na Moda tendo como fundamentação teórico-metodológica a TRS. Embora tenhamos focalizado professores e alunos de cursos de formação nessa área, a temática pode afetar outros sujeitos/grupos, como gestores de cursos, empresários e trabalhadores do setor. Uma pista de pesquisa seria investigar como está acontecendo a familiarização dos sujeitos com esse objeto, consequentemente como se objetivam e onde se ancoram as representações sociais de upcycling para diversos grupos, os quais interagem em contextos complexos de comunicação, com acessos variados à informação. Esses processos se refletem em crenças e valores que sustentam a elaboração e o compartilhamento de um conhecimento do senso comum, o qual se expressa em esquemas imagéticos contextualizados em uma cultura.

Outra possibilidade de pesquisa éa análise dimensional das representações de upcycling elaboradas por diversos grupos do universo da Moda, buscando suas fontes de informação, a imagem que condensa o significado do objeto para esses grupos, suas posições, ou orientações favoráveis ou desfavoráveis, em relação ao objeto, com as respectivas explicações. Um aspecto que pode ser também considerado nas pesquisas são os determinantes sociais das representações, ou seja, o modo como as interações sociais demandam que os sujeitos tomem posições (pressão à inferência), a atenção dos sujeitos direcionada a certos dados da realidade social (focalização) e o tipo de informação acessada dependendo das condições pessoais e sociais dos sujeitos (defasagem e dispersão de informação).

O caráter interdisciplinar e plurimetodológico da TRS se adequa aos estudos da área da Moda (BORGES, 2018). É nesse contexto que o referencial pode (re) pensar questões sociais, econômicas e políticas associadas ao tema, principalmente no que diz respeito à pesquisa e à formação em Moda. São inúmeras as possibilidades 
de estudar as relações entre as dimensões psicológica e social na elaboração das representações, as interferências recíprocas para a compreensão do que se mantém ou do que muda no pensamento social, como bem propôs Alves-Mazzotti (2008b).

Um dos fundamentos epistemológicos da TRS, a tríade "Sujeito-OutroObjeto" (MOSCOVICI, 1984), é também fundamental a ser considerada nos estudos relacionados à pesquisa e à formação em Moda, no âmbito de uma abordagem psicossocial. São múltiplas e diversas, portanto, as possiblidades para estudar o upcycling, tema que vem chamando cada vez mais a atenção de acadêmicos e profissionais da área da Moda. Entendendo que a representação social é o processo pelo qual um grupo assimila um conhecimento novo e o ressignifica, e diante da escassez de trabalhos acadêmicos sobre o tema upcycling, consideramos que este é um momento oportuno para pesquisarmos representações sociais de upcycling para grupos distintos, pois, ao que parece, há ainda um processo de familiarização com o termo nesse universo.

\section{CONSIDERAÇÕES FINAIS}

Este artigo teve a intenção de refletir, de maneira não exaustiva, sobre as possiblidades da TRS para estudos de upcycling na área da Moda, visando ampliar o olhar para as diversas questões que envolvem a temática da sustentabilidade.

Acreditamos que estudar representações sociais de upcycling pode ajudar a entender processos formativos, especialmente de Moda e no Design, e como os cursos estão lidando com a apropriação do termo. De que modo as instituições estão, efetivamente, preparando os estudantes para o mundo do trabalho, onde os temas relativos à sustentabilidade já são abordados? É dessas instituições que sairão os futuros profissionais para trabalharem na área, logo, é importante que preparem futuros profissionais mais atentos e envolvidos para colocarem em prática o tripé ambiental, econômico e social no qual se apoia a sustentabilidade.

O presente artigo não pretendeu encerrar as reflexões sobre nenhum dos temas abordados. Upcycling, sustentabilidade, Moda e representações sociais, e suas articulações, são campos férteis para aprofundamento de pesquisas. Nossa intenção aqui foi contribuir para (re)pensar as relações entre os temas citados.

Entendemos, portanto, que é relevante estudar a representação social de upcycling que está sendo formada por diversos grupos da área da Moda, bem como investigar como informações sobre o tema são veiculadas por diversas fontes, incluindo as acadêmicas. A reflexão teórica aqui apresentada indicou que o modo como o tema é tratado em diversos contextos sociais e culturais pode interferir nas representações sociais de upcycling elaboradas pelos grupos, assim como em suas práticas. $^{3}$

3 Revisora gramatical - Maria Inêz Afonso Fernandes da Paz, Licenciatura em Letras - Português - Espanhol pela UFRJ - e-mail: inezdapaz@hotmail.com 


\section{REFERÊNCIAS}

ABRIC, J. C. In: SÁ, C. P. Núcleo central das representações sociais. Petrópolis, RJ: Vozes. 1996.

ALVES-MAZZOTTI, A. J. Representações sociais: aspectos teóricos e aplicações à educação. Revista Múltiplas Leituras, v. 01, n. 01, p. 18-43, jan./jun. 2008a. Disponível em: https://www. metodista.br/revistas/revistas-ims/index.php/ML/article/ view/1169/1181. Acesso em: 20 abr 2020.

ALVES-MAZZOTTI, A. J. Representação do trabalho do professor das séries iniciais: a produção do sentido de "dedicação". Revista Brasileira de Estudos Pedagógicos, Brasília, v. 89, n. 223, p. 522-534, set./dez. 2008b. Disponível em: http://rbep.inep.gov.br/index.php/rbep/article/ view/690/668. Acesso em: 20 abr 2020.

AVILA, A. P. S.; MACIEL, D. M. H.; SILVEIRA, I.; RECH, S.R. Resíduos têxteis sólidos no contexto de abordagens sustentáveis. Mix Sustentável. Florianópolis. v.4. n.3. p.17-24. out-mar. 2018. Disponível em: http://ojs.sites.ufsc.br/index.php/ mixsustentavel/article/view/2555/2500. Acesso: 10 jun 2020.

BERLIM, L. Moda e Sustentabilidade: Uma reflexão necessária. São Paulo: Estação das Letras e Cores. 2012. Edição Kindle.

BERNAL, M. B.; Sustentabilidade na Política Internacional da Moda: Uma análise crítica acerca do discurso do consumo consciente. 2019. Artigo Científico. (Instituto de Relações Internacionais da Pontifícia Universidade Católica do Rio de Janeiro) PUC-Rio. 2019. Disponível em: https://ufrrj. academia.edu/MarianaBernal. Acesso em: 02 jun 2020.

BORGES, M. S. Representação social de "ser profissional" da área de moda por alunos, professores e empresários do setor no Rio de Janeiro, em São Paulo e em Nova York. 2018. 236 f. Tese (Doutorado em Educação) - Programa de Pós-Graduação em Educação, Universidade Estácio de Sá, Rio de Janeiro, 2018. Disponível em: https://portal.estacio.br/cursos/mestrado-edoutorado/educa\% C3\%A7\%C3\%A3o/disserta\%C3\%A7\%C3\%B5es-e-teses/. Acesso em: 10 jun 2020.

BRAUNGART, M.; MCDONOUGH, W. Cradle to Cradle - Criar e Reciclar llimitadamente. Tradução de Frederico Bonaldo. São Paulo: Editora Gustavo Gili, $1^{\text {a }}$ Ed. 2014. Edição Kindle.

BRUNDTLAND, G. H. Nosso futuro comum: comissão mundial sobre meio ambiente e desenvolvimento. 2.ed. Rio de Janeiro: Fundação Getúlio Vargas, 1991.

CAMPOS, P. H. F. O estudo da ancoragem das Representações Sociais e o campo da Educação. Revista de Educação Pública. v.26, $n^{\circ} 63$ (2017). Disponível em: http://periodicoscientificos.ufmt. br/ojs/index.php/educacaopublica/article/view/4187. Acesso em: 03 mai 2020.

CARREIRA, G., Martin Margiela: o estilista invisível. 21 Junho de 2019 - Disponível em: https:// www.farfetch.com/br/style-guide/icones-de-estilo-e-influenciadores/martin-margiela-o-estilistainvisivel/. Acesso em: 10 jun 2020.

CRUL, M.R.M.; DIEHL, J.C. Diseño para la Sostenibilidad: Un enfoque práctico para economías en dessarollo. UNEP. Paris, 2007. Disponível em: www.d4s-de.org/d4sspanishlow.pdf. Acesso em: 25 fev 2021.

ELKINGTON, J. Cannibals with forks: The triple bottom line of 21st Century Business. Oxford Centre for Innovation. Oxford: Capstone Publishing Limited. 1997.

FLETCHER, K.; GROSE, L. Moda \& Sustentabilidade: Design para mudança. Traduzido por Janaína Marcoantonio. São Paulo: Editora Senac. 2019. Edição

Kindle. 
FREITAS, R. F. Na moda: Simmel, cultura e consumo. 2001. Disponível em: https://www.epublicacoes.uerj.br/index.php/logos/article/view/14759/11207. p. 41. Acesso em: 30 ago 2019.

GWILT, A. Integrating sustainable strategies in the fashion design process: a conceptual model of the fashion designer in haute couture. 2012. 191 p. Thesis (Doctor of Philosophy) College of Design and Social Context, RMIT University, Melbourne, 2012.

JODELET, D. Représenttion sociale: phénomène, concept et théorie. In: MOSCOVICI, Serge. Psychologie sociale. Paris: Presses Universitaires de France, 1984.

JODELET, D. Representações Sociais: um domínio em expansão. In: JODELET, D. (Org.). As Representações Sociais. Tradução Lílian Ulup. Rio de Janeiro: EdUERJ, 2001. p. 17-44.

JODELET, D. A fecundidade múltipla da obra "A Psicanálise, sua imagem e seu público". In: ALMEIDA, A.M. de O.; SANTOS, M.F.S.; TRINDADE, Z.A. Teoria das Representações Sociais 50 anos. Brasília: Technopolitik, 2011, p. 199-223.

KÖHLER SCHULTE, N. et al. A moda no contexto da sustentabilidade. ModaPalavra e-periódico, no. 12, jul-dez, p. 194-210. UDESC, Florianópolis, 2013. Disponível em: http://www.redalyc.org/ articulo.oa? id $=514051625013$. Acesso em: 06 fev. 2021.

LIMA, B. L. Estratégias de design para pós-produção de produtos de moda. 2019. 238 f. Tese (Doutorado em Design) - Programa de Pós-Graduação em Design da UFRGS. Porto Alegre, 2019.

LIMA, R. C. P.; CAMPOS, P. H. F. Núcleo figurativo da representação social: contribuições para a educação. Educ. rev., Belo Horizonte, v. 36, e206886, 2020. Epub May 08, 2020. Disponível em: . https://www.scielo.br/scielo.php?script= sci_arttext\&pid=S0102-46982020000100208. Acesso em: 13 jun 2020.

LIPOVETSKY, G. Império do Efêmero. São Paulo: Companhia das Letras,1989.

LOCKTON, D.; HARRISON, D. J.; STANTON, N. A. The Design with Intent Method: a design tool for influencing user behaviour. Applied Ergonomics, v. 41, no. 3, p. 382-392, May 2010. Disponível em: http://dx.doi.org/10.1016/j.apergo.2009.09.001. Acesso em: 05 jun 2020.

MANZINI, E.; VEZZOLI, C. O desenvolvimento de produtos sustentáveis: os requisitos ambientais dos produtos industriais. São Paulo: Editora da Universidade de São Paulo, 2008.

MAROTTO, I. Mais sustentabilidade às marcas de moda: Reflexões e Indicadores. Org. Isabela Marotto, 2017. Disponível em: http://porfavormenoslixo. com.br/wp-content/ uploads/2018/01/LIVRO-SUSTENTABILIDADE-\%C3\%80S-MARCAS-DE-MODA.pdf. Acesso: 14 nov.2019

MARTELI, I; PASCHOARELLI, L. C.; et al. Slowfashion: conceitos que estabelecem essa cultura de consumo - uma revisão. Revista Achiote.com - Revista Eletrônica de Moda - v. 6. n 2. Dez. 2018. Disponível em: http://www.fumec.br/revistas/ achiote/article/view/6586. Acesso em: 05 jun 2020.

MOSCOVICl, S. La psychanalyse, son image et son public. Paris: Presses Universitaires de France, 1961.

MOSCOVICI, S. La psychanalyse, son image et son public. Paris: Presses Universitaires de France, 1976.

MOSCOVICl, S. Le domaine de la psychologie sociale. In: MOSCOVICI, S. La psychologie sociale. Paris: PUF, 1984. 
MOSCOVICI, S. Das representações coletivas às representações sociais: elementos para uma história. In: JODELET, D. (Org.) As Representações Sociais. Tradução Lílian Ulup. Rio de Janeiro: EdUERJ, 2001. p. 45-66.

MOSCOVICI, S. Por que estudar representações sociais em Psicologia? Estudos, vida e saúde, [S.I.], Goiânia, v. 30, n. 1, p. 11-30, 2003.

MOSCOVICI, S. A Psicanálise, sua imagem e seu público. Tradução de Sonia Fuhrmann. Petrópolis: Vozes, 2012.

MOSCOVICI. S. Representações Sociais: Investigações em Psicologia Social. 11a. ed. Petrópolis: Vozes, 2015.

NICOLINI, F. Upcycling e Acessórios. In: MAROTTO, Org. Mais sustentabilidade às marcas de moda: Reflexões e Indicadores. Rio de Janeiro, E-book. 2017. p. 155-168. Disponível em: http:// porfavormenoslixo.com.br/wp-content/uploads/2018/01/LIVRO-SUSTENTABILIDADE-\%C3\%80SMARCAS-DE-MODA.pdf. Acesso em: 29 mai 2020.

PILZ, R. Entrevista concedida a Salvo News, Reino Unido, n² 23, p. 11-14, Outubro, 1994.

PINHEIRO, C. M.; STEINHAUS, C.; CHERUTTI, M. Um estudo sobre terminologias de sustentabilidade na moda. In: IARA - Revista de Moda, Cultura e Arte. São Paulo, Vol. 10 n. 1 - Dezembro. 2018, p. 23: Centro Universitário Senac. Disponível em: http://www1.sp.senac.br/ hotsites/blogs/revistaiara/wpcontent/uploads/2018/12/ IARA-2.pdf. Acesso em: 25 set 2019.

RATEAU, P.; MOLINER. P.; GUIMELLI, C.; ABRIC, J.-C. Social Representation Theory. In: Van Lange, P. A. M.; Kroglanski, A. W.; Higgins, R. T. (Org.) Handbook of Theories of Social Psychology, v. 2. London: SAGE, 2012, P. 477-497.

RUDOLPH, L. T. B. Regras limpas e roupas sujas: uma abordagem institucional para a ética no varejo de moda e vestuário. 2017. Tese (Doutorado) FEAUSP, São Paulo, 2017. Disponível em: https://www.fea.usp.br/administracao/eventos/ doutorado-regras-limpas-e-roupas-sujas-umaabordagem-institucional-para-etica. Acesso em: 18 out 2019.

SÁ, C.P. As representações sociais na história recente e na atualidade da Psicologia Social. In: JACÓ-VILELA, A.M.; FERREIRA, A.A.L.; PORTUGAL, F.T. História da Psicologia - Rumos e percursos. Rio de Janeiro: Nau, 2011.

SALES, G. M. J. Representações Sociais da Cultura de Moda Regional - 2007. Disponível em: ttp://www.coloquiomoda.com.br/anais/Coloquio\%20de\%20Moda\%20-\%202007/4_02.pdf. Acesso em: 30 mai 2020.

SALVO NEWS, Reino Unido, n²3, p. 11-14, outubro, 1994.

SANTOS, M.F.S. A Teoria das Representações Sociais. In: SANTOS, M.F.S., ALMEIDA, L.M. (orgs) Diálogos com a Teoria das Representações Sociais. Recife: EdUFPE, 2005, p.15-38.

SILVEIRA, L. M. Inovação Social e Sustentabilidade na Moda: Proposta de solução habilitante para reaproveitamento de resíduos têxteis. 110 f. Dissertação (Mestrado) - Programa de PósGraduação em Design, Universidade do Vale do Rio dos Sinos - UNISINOS. Porto Alegre, 2019. Disponível em: http://www.repositorio.jesuita.org.br > UNISINOS. Acesso em: 03 de fev. 2021.

SOUSA, C. P. Estudos de representações sociais em educação. Psicologia da Educação. Revista do Programa de Estudos Pós-Graduados/PUC-SP. São Paulo, 14/15, $1^{\circ}$ e $2^{\circ}$ sem. Dez 2002, p. 285-323. Disponível em: https://revistas. pucsp.br/psicoeduca/article/view/32037/22177. Acesso em: 20 mar 2020. 
SUNG, K. A Review on Upcycling: Current Body of Literature, Knowledge Gaps and a Way Forward. Venice. Italy Apr 13-14, 2015, 17 (4) Part I. Disponível em: https://www.researchgate.net/ publication/299559229_A_Review_on_Upcycling_Current_Body_of_Literature_Knowledge_Gaps_ and_a_Way_Forward. Acesso em: 12 jun 2020

ZONATTI, W. F. Estudo interdisciplinar entre reciclagem têxtil e o design: avaliação de compósitos produzidos com fibra de algodão. 195 f. Dissertação (Mestrado em Têxtil e Moda) Escola de Artes, Ciências e Humanidades, Universidade de São Paulo - USP, São Paulo, 2013. Disponível em: https://www.teses.usp.br/teses/disponiveis/100/100133/tde-13032013-015305/ publico/mestrado.pdf. Acesso em: 25 set 2019 